Marquette University

e-Publications@Marquette

College of Nursing Faculty Research and

Publications

Nursing, College of

$1-1-2014$

Family Caregivers' Knowledge of Delirium and Preferred Modalities for Receipt of Information

Margaret J. Bull

Marquette University, margaret.bull@marquette.edu

Lesley Boaz

Marquette University, lesley.boaz@marquette.edu

Jennifer M. Sjostedt

Marquette University

Accepted version. Journal of Applied Gerontology, Vol 35, No. 7 (July 2014): pg. 744-758. DOI. (C) 2014 SAGE Publications. Used with permission. 
NOT THE PUBLISHED VERSION; this is the author's final, peer-reviewed manuscript. The published version may be accessed by following the link in the citation at the bottom of the page.

\title{
Family Caregivers' Knowledge of Delirium and Preferred Modalities for Receipt of Information
}

\author{
Margaret J. Bull \\ College of Nursing, Marquette University, \\ Milwaukee, WI \\ Lesley Boaz \\ Marquette University, Milwaukee, WI \\ Jennifer M. Sjostedt \\ Marquette University, Milwaukee, WI
}

\begin{abstract}
Delirium is a life-threatening, frequently reversible condition that is often a sign of an underlying health problem. In-hospital mortality alone for older adults with delirium ranges from $25 \%$ to $33 \%$. Early recognition of delirium is critical because prolonged duration poses a greater risk of poor functional outcomes for older adults. Family caregivers, who are familiar with the older adult's usual behaviors, are most likely to recognize delirium symptoms but might dismiss them as due to aging. It is important to learn what family caregivers know about delirium to ascertain their need for education. The aims of this study were to describe family caregivers' knowledge of delirium and preferred modalities for receipt of information about delirium. A cross-sectional design was used for this study and a survey distributed to family caregivers for older adults. Analysis of 134 usable surveys indicated that family caregivers need and want information about


NOT THE PUBLISHED VERSION; this is the author's final, peer-reviewed manuscript. The published version may be accessed by following the link in the citation at the bottom of the page.

delirium. The preferred modalities for receipt of information included Internet, in-person classes, and newsletters.

Keywords delirium, family caregivers, older adults

Delirium has significant negative consequences for older adults and the health care system. For older adults, in-hospital mortality rates alone range from $25 \%$ to $33 \%$. Estimates of the cost of delirium for the United States health care system range from $\$ 38$ to $\$ 152$ billion annually, with higher costs associated when delirium is superimposed on dementia (Leslie \& Inouye, 2011; Leslie, Marcantonio, Zhang, Leo-Summers, \& Inouye, 2008).

Delirium is a life-threatening, frequently reversible condition characterized by sudden onset and fluctuations in orientation, memory, disorganized thinking, perceptual disturbances, and compromised ability to communicate (Bond, 2009; Leslie \& Inouye, 2011; Sykes, 2012). Delirium is frequently a sign of an underlying illness or health problem that requires a medical evaluation (Bond, 2009; Dasgupta \& Hillier, 2010; Rahkonen et al., 2000). Common illnesses or health problems for which delirium is a presenting symptom include infections, metabolic disturbances, dehydration, hypoxia, pain, and reactions to medications (Dasgupta \& Hillier, 2010; Meagher et al., 2011; Meier, 2012; Rahkonen et al., 2000). Delirium occurs more often in older adults who have dementia than in persons without cognitive impairment (Fick, Agostini, \& Inouye, 2002; Fong et al., 2009); however, the symptoms of delirium and cognitive impairment in general often are not recognized by health care providers who are unfamiliar with the older adult's cognitive baseline (Boustani et al., 2010; Fick \& Foreman, 2000; Greer et al., 2011; Martinez, Tobar, Beddings, Vallejo, \& Fuentes, 2012). Symptoms of delirium are often attributed to the dementia or to normal aging, thereby delaying diagnosis and treatment of the underlying cause of delirium (Fick et al., 2002; Mittal et al., 2011; Wang \& Mentes, 2009).

Prolonged duration of delirium presents a greater risk of poor functional outcomes in older adults than situations in which delirium is recognized early and the underlying cause treated (Kiely et al., 2009; Quinlan \& Rudolph, 2011). Failure to recognize delirium early contributes to increased risk of falls, a cascade of functional decline, lengthy hospital stays, institutionalization, and increased mortality for

Journal of Applied Gerontology, Vol 35, No. 7 (July 2014): pg. 744-758. DOI. This article is @ SAGE Publications and permission has been granted for this version to appear in e-Publications@Marquette. SAGE Publications does not grant permission for this article to be further copied/distributed or hosted elsewhere without the express permission from SAGE Publications. 
older adults (Bellelli et al., 2007; González et al., 2009; Leslie \& Inouye, 2011; Rudolph et al., 2010; Witlox et al., 2010). In fact, mortality increased $11 \%$ for every $48 \mathrm{hr}$ that delirium went unrecognized (González et al., 2009). Clearly, early recognition of delirium symptoms is critical to prevent negative sequelae in older adults.

Family members provide care for more than $75 \%$ of older adults with dementia (Alzheimer's Association, 2010). These family caregivers are most likely to recognize changes in the older adult's mental status early because they are familiar with the older adult's usual behaviors (Fick \& Foreman, 2000). However, family caregivers often attribute the mental status change to progression of the dementia or aging (Bull, 2011; Naylor et al., 2007). As a result, family caregivers might not encourage the older adult to seek a medical evaluation. In addition to the negative consequences for older adults, a few studies found that family caregivers reported feeling frightened, anxious, frustrated, and unprepared for the behaviors that accompanied the older adult's delirium (Bruera et al., 2009; Buss et al., 2007). However, previous studies have not identified what family caregivers know about delirium or their ability to recognize delirium symptoms in community dwelling older adults with dementia. Although the findings of previous studies describe family caregivers' reactions to Internet interventions and suggest that younger adults are more likely to prefer computer technologies than older adults (Bunz, 2009; Chiu \& Eysenbach, 2010; Hayden, Glynn, Hahn, Randall, \& Randolph, 2012; Lewis, Hobday, \& Hepburn, 2010; National Alliance for Caregiving \& American Association of Retired Persons, 2009; Quinn, 2010), no studies to date have explored family caregivers' preferred modalities for receipt of information about delirium.

The aims of this study were to describe family caregivers' knowledge of delirium and their preferred modalities for receipt of information about delirium. Acquiring information on the degree of family caregiver knowledge about delirium, interest in delirium education, and preferred information modalities is a critical first step in designing educational interventions to promote early recognition of delirium symptoms. 
NOT THE PUBLISHED VERSION; this is the author's final, peer-reviewed manuscript. The published version may be accessed by following the link in the citation at the bottom of the page.

\section{Method}

\section{Study Design}

A descriptive, cross-sectional survey design was used for this study. Cross-sectional designs are appropriate when the research aims to describe the status of a phenomenon (Polit \& Beck, 2012). The Family Caregiver Delirium Knowledge Questionnaire (CDKQ), which was developed specifically for this study, was distributed to two samples of family caregivers (individuals who identified themselves as family members providing care). After the University's Institutional Review Board's (IRB) approval was obtained, the questionnaire was mailed via the postal system to 400 family caregivers in Sample 1 with a response rate of $20 \%$. An email that provided a link for accessing the questionnaire on the Internet was sent to 417 family caregivers in Sample 2 and yielded a response rate of $14.6 \%$.

\section{Sample Selection}

A total of 139 family caregivers responded to the survey. Sample 1 was obtained from a mailing list provided by a local chapter of the Alzheimer's Association. Residential zip codes were identified using U.S. Census data that provided demographic characteristics of the residents in each area of a large city in the Midwest. Fifteen family caregivers were systematically selected from each of the 26 residential zip codes. There were two zip code areas for which the Alzheimer Association's list had fewer than 15 family caregivers so additional family caregivers were selected from zip codes that had a high proportion of minority and low income residents. Sample 2 was obtained from a Family Caregiver Registry maintained by a researcher at a university in a Midwestern city. All family caregivers in the registry received the email invitation to complete the questionnaire. Data from three Internet respondents were excluded from the analysis because they indicated they did not give consent although they completed the questionnaire. Four respondents who received the mailed survey completed the first page of the questionnaire and provided demographic information but wrote that they did not know anything about delirium and so did not complete the CDKQ. When these participants were eliminated, it yielded a total of 134 usable surveys. 
NOT THE PUBLISHED VERSION; this is the author's final, peer-reviewed manuscript. The published version may be accessed by following the link in the citation at the bottom of the page.

\section{Instrument}

\section{$C D K Q$}

The CDKQ was developed specifically for this study because a valid, reliable measure was not located in the literature. The CDKQ consists of 19 items (yes/no/don't know response) and 3 subscales Risk, Action, and Symptoms). The ratio of correct items for the Risk subscale was 7:10, for the Action subscale was $1: 4$, and for the symptom subscale was 3:5. Correct responses received a score of 1 and incorrect responses a score of 0 . Responses of "don't know" also received a score of 0 . The three delirium knowledge subscales (Risk, Action, and Symptoms) were based on the symptom interpretation framework (Teel, Meek, McNamara, \& Watson, 1997). Items for the CDKQ were derived based on the symptom interpretation framework and a review of the delirium literature. Content validity was established by having three experts (two gerontological nurse practitioners and a nationally recognized nurse expert in delirium) review the items for content and clarity. There was $100 \%$ agreement among the content experts on the items in each category (Risks, Action, and Symptoms), and these experts recommended sequencing the questions in the order of risks, actions, and symptoms.

Modifications were made to improve item clarity based on feedback from two older adults who had experience with caregiving. Construct validity was established by conducting factor analysis with data from 164 family caregivers. Internal consistency reliability of the total instrument was .76, which is considered acceptable for a new instrument (Polit \& Beck, 2012). Internal consistency reliability for the total instrument with the sample of 134 family caregivers in this study was .75. A seventh-grade reading level was assessed using the FleishKincaid software.

\section{Findings}

The average age of family caregivers was 60.9 years $(S D=$ $13.5)$; the majority $(85.1 \%)$ was White. Education level ranged from fifth grade through graduate school with a mean of 15.5 years ( $S D=$ $2.8)$. The majority of the respondents were female $(81.3 \%)$, married $(85.8 \%)$, and had been providing care for their family member for an

Journal of Applied Gerontology, Vol 35, No. 7 (July 2014): pg. 744-758. DOI. This article is @ SAGE Publications and permission has been granted for this version to appear in e-Publications@Marquette. SAGE Publications does not grant permission for this article to be further copied/distributed or hosted elsewhere without the express permission from SAGE Publications. 
average of 5.9 years $(S D=7.0)$. As noted in Table 1 , family caregivers in the Internet sample were younger, less ethnically diverse, and had more years of education than family caregivers who received the mailed survey.

Table I. Demographic Characteristics of Samples I and 2.

\begin{tabular}{lcc}
\hline Demographics & Sample I $(n=76)$ & Sample 2 $(n=58)$ \\
\hline Age-M (SD) & $62.01(15.50)$ & $59.43(10.29)$ \\
$\quad$ Range & $23-94$ year & $21-80$ year \\
Education-M (SD) & $14.58(2.84)$ & $16.74(2.35)$ \\
$\quad$ Range & $5-18$ year & $12-24$ year \\
Female & $78.9 \%$ & $84.5 \%$ \\
Race & $78.3 \%$ & \\
White & $14.5 \%$ & $96.6 \%$ \\
Black & $9.2 \%$ & $0 \%$ \\
Hispanic & $0 \%$ & $0 \%$ \\
Asian & & $1.7 \%$ \\
\hline
\end{tabular}

Most of the family caregivers (78\%) expressed interest in receiving information about delirium although $55.6 \%$ indicated that they knew about delirium. To identify acceptable modalities, family caregivers were asked to check all preferred modalities for receiving information about delirium. The most frequently identified modalities were Internet (54.5\%), newsletter (50\%), and in-person class $(36.6 \%)$. Family caregivers who were under 65 years of age indicated a preference for receiving information via Internet more often than those above 65 years of age, $\mathrm{X}^{2}=7.55, p<.01$. There was no difference between family caregivers under 65 years of age and those above 65 years of age on preference for in-person classes, $x^{2}=0.53$, $p=.29$, or receipt of information via newsletter, $x^{2}=2.01, p=.10$.

Family caregivers' responses on the total scale of the CDKQ ranged from 0 to 19 with an average score of 11.54 ( $S D=3.59$ ). Family caregivers' responses on the Risk subscale ranged from 0 to 10 with a mean of $6.44(S D=1.94)$. As noted in Figure 1 , family caregivers had fewer incorrect responses for risk factors of having dementia, age 70 years or older, receiving a new medication, dehydration, a change in environment, having a surgical procedure, and having an infection. Family caregivers' scores on the Action 
subscale ranged from 0 to 4 with a mean of $2.39(S D=1.42)$. The bar chart in Figure 2 illustrates family caregivers' responses to actions that they would take if an older adult family member developed sudden confusion. Incorrect responses included that $35.1 \%$ of the family caregivers would not call a doctor, $44.7 \%$ indicated they would wait a week to see whether the condition improved before taking action, approximately $54 \%$ would give the older adult tea or warm milk to drink, and $27.6 \%$ would do nothing. Scores on the Symptom subscale ranged from 0 to 5 with a mean of $2.71(S D=1.36)$. The bar chart in Figure 3 illustrates family caregivers' incorrect responses or lack of delirium symptom recognition. Approximately $64 \%$ of the family caregivers incorrectly identified Symptom 2 (situation in which an older adult slowly becomes more confused over a few months and later in the day "sundowns") as a symptom of delirium. More than half $(54.5 \%)$ of the family caregivers did not recognize Symptom 5 (older adult becomes more confused over a few days and suddenly has trouble getting to the bathroom) as a symptom of delirium. Nearly half $(47.8 \%)$ of the family caregivers incorrectly identified Symptom 1 (older adult slowly becomes more confused over a few months, is forgetful) as a sign of delirium. Symptom 4 (older adult suddenly becomes confused over a few days or hours, sleeps more during the day) was not recognized by $40.2 \%$ of the family caregivers as a symptom of delirium. Symptom 3 (older adult suddenly becomes confused over a few days and sees things that are not there) was not recognized as a symptom of delirium by $22.4 \%$ of the family caregivers.

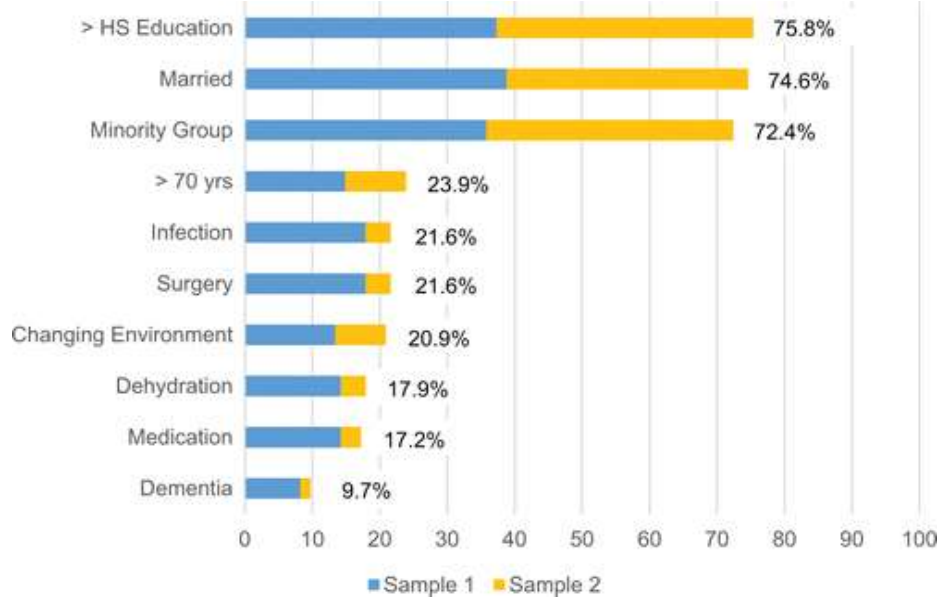

Figure 1. Percentage incorrect responses: Risks for delirium. Note. HS refers to high school education

Journal of Applied Gerontology, Vol 35, No. 7 (July 2014): pg. 744-758. DOI. This article is @ SAGE Publications and permission has been granted for this version to appear in e-Publications@Marquette. SAGE Publications does not grant permission for this article to be further copied/distributed or hosted elsewhere without the express permission from SAGE Publications. 
NOT THE PUBLISHED VERSION; this is the author's final, peer-reviewed manuscript. The published version may be accessed by following the link in the citation at the bottom of the page.

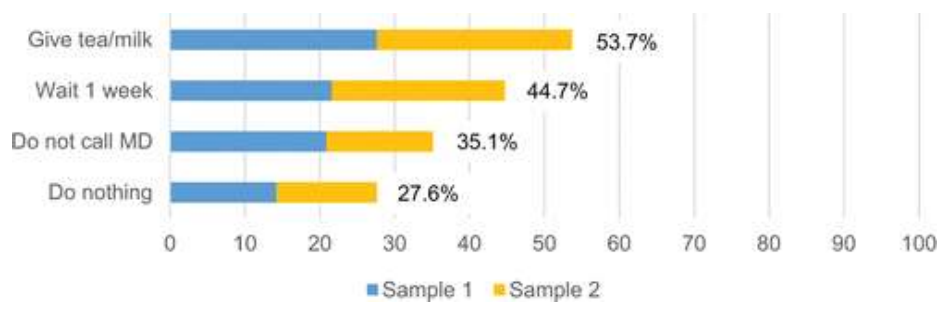

Figure 2. Percentage incorrect responses: Actions for delirium. Note. MD refers to medical doctor.

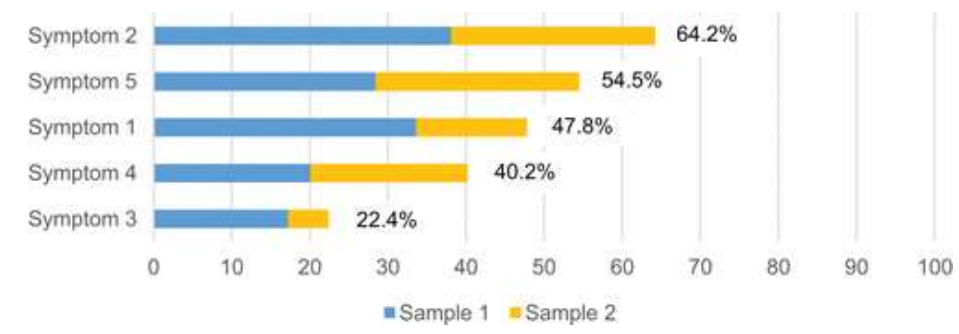

Figure 3. Percentage incorrect responses: Symptoms ${ }^{a}$ of delirium.

aNote. Symptom 1: (Not delirium) Older adult slowly becomes more confused over a few months. Symptom 2: (Not delirium) Older adult slowly becomes more confused over a few months and hallucinates. Symptom 3: (Delirium) Older adult suddenly becomes confused over a few days or hours and hallucinates. Symptom 4: (Delirium) Older adult suddenly becomes confused over a few days or hours and sleeps more during the day. Symptom 5: (Delirium) Older adult becomes more confused over a few days.

\section{Discussion}

The findings of this study indicate that most of the family caregivers in this sample were familiar with common risk factors for delirium (i.e., having dementia, infection, dehydration, age above 70 years, receiving a new medication). However, recognizing symptoms of delirium presented more of a challenge. Family caregivers appeared to confuse symptoms of delirium with dementia. Because the sample consisted of family caregivers who had experience with caring for an older adult with dementia, they might have thought delirium was the same as dementia. In fact, the pattern of responses on the Symptom subscale suggested that both gradual and sudden changes in cognitive status were viewed as delirium symptoms. The inability to distinguish delirium and dementia symptoms might have influenced family caregivers' response to the items on the Action subscale as it was clear that they did not think immediate action was necessary when an older adult suddenly became confused. It was surprising that $44.7 \%$ would wait a week to see whether the condition improved and $27.6 \%$ would do nothing. Given the negative outcomes associated with prolonged 
duration of delirium (Bellelli et al., 2007; González et al., 2009), a delay in early detection of symptoms and seeking treatment has critical implications for the health and well-being of older adults.

The findings indicate that family caregivers need education on delirium symptoms and the appropriate action to take when these symptoms are observed. It is imperative that they receive information not only on risks and possible causes but also on the symptoms and appropriate actions to take when the symptoms are observed to promote early intervention for the older adults. Educating family caregivers on delirium symptoms and appropriate actions to take might increase the number of family caregivers who take prompt action in contacting the older adult's health care provider when delirium symptoms are observed.

Our findings that family caregivers above 65 years of age were less likely to prefer Internet delivery of information support findings from studies with older adults and from studies of family caregivers for persons with dementia (Hayden et al., 2012; National Alliance for Caregiving \& American Association of Retired Persons, 2009; Quinn, 2010). While some studies reported that older adults were less inclined to use or prefer computer technologies (National Alliance for Caregiving \& American Association of Retired Persons, 2009; Quinn, 2010), others described the difficulties that adults above 70 years of age had with simple web tasks even after receiving several hours of telephone support for an Internet intervention (Hayden et al., 2012). Although Lewis and colleagues reported that their Internet intervention was positively received, the mean age of family caregivers in their study was 55 years, of whom $85 \%$ were White and $65 \%$ were college educated. Chiu and Eysenbach (2010) contend that attitudes toward technology were more important than age in determining attrition from interventions using technology; however, only four family caregivers ( $11.4 \%$ of their study participants) were above 65 years of age. Studies reporting use of Internet interventions with family caregivers for persons with dementia did not query participant preferences; instead, the authors' either reported the challenges older adults encountered in using the technology and attrition rates or the family caregivers' response to the intervention (Hayden et al., 2012; Lewis et al., 2010). It is important to consider the preferred modalities for receipt of information when designing effective educational permission has been granted for this version to appear in e-Publications@Marquette. SAGE Publications does not grant permission for this article to be further copied/distributed or hosted elsewhere without the express permission from SAGE Publications. 
intervention to meet the needs of family caregivers and to promote retention in intervention studies. The findings from our study indicate that irrespective of age, family caregivers found newsletters and inperson group classes acceptable forms of education. In planning an Internet intervention, one needs to be aware that people above 65 years of age, those who are ethnically diverse, and those who have lower level of education might be less likely to participate in the intervention. Thus, when health care providers are designing interventions or educational materials for family caregivers, confirming the preferred modality for receipt of information is an essential step in meeting the family caregiver's educational needs and preventing attrition. Researchers and program planners can use information on preferred modalities to weigh the cost of modalities, the resources available, and the characteristics of the target population.

Health care providers can use the information on family caregiver knowledge of delirium to design educational interventions that prepare family caregivers to partner with health care providers in early detection of delirium symptoms. Assessing family caregiver delirium knowledge can provide a basis for tailoring interventions to specific target groups. Providing family caregivers with information on symptom recognition in addition to the negative health consequences associated with delirium duration and the importance of early recognition of symptoms might lead to improved health outcomes for older adults at risk of delirium. Considering that previous studies (Bruera et al., 2009; Buss et al., 2007) found that family caregivers experienced fear and anxiety when they encountered behaviors associated with delirium, educating family caregivers about delirium might also alleviate their frustrations and fears.

\section{Limitations}

Limitations of this study included the characteristics of respondents and the response rates. Despite attempts to oversample minority populations, there was limited representation of minorities in the sample. The response from minorities in the mailed sample was higher than in the Internet sample (20\% compared with $14.6 \%$ ), reflecting demographics in the geographic area and perhaps family caregivers' preference for ways of giving and receiving information. It 
is important to note that the high percentage of White family caregivers in the Internet sample was fairly representative of the geographic area from which the sample was obtained. An additional limitation related to respondent characteristics is that the survey did not ask family caregivers to indicate their relationship to the older adult. The literature did not indicate that family caregivers' need for information on delirium might differ by relationship; however, it is possible that modality preferences might differ. To some extent, age might serve as a proxy for relationship because spousal caregivers might be older than children providing care for parents.

Response rates to mailed survey questionnaires vary greatly in both postal and email surveys; however, our rates of $20 \%$ for the mailed survey and $14.6 \%$ for the Internet survey were lower than expected. A review of response rates in studies found rates ranging from $22 \%$ to $68.8 \%$ in Whites; and rates ranging from $15.4 \%$ in African Americans to $70.9 \%$ in Hispanics. However, the authors concluded there were no significant differences in response rates by ethnicity ( Sykes, Walker, Ngwakongnwi, \& Quan, 2010). Mailed surveys typically had a lower response rate than telephone surveys or surveys distributed in person (Edelman, Rumei, Maughan, \& Olson, 2013; L. L. Sykes et al., 2010). Although we were able to send a follow-up reminder to the Internet sample, the reminder did not yield an appreciable increase in the response rate. The response rate was better $(20 \%)$ from the mailed questionnaires although it was not possible to send reminders to the family caregivers associated with the local chapter of the Alzheimer's Association because of the organization's confidentiality restrictions. Although we limited the survey to two pages to reduce response burden, it is possible that the low response rates might reflect the time constraints that family caregivers experience when balancing the demands of providing care with other commitments.

\section{Recommendations for Future Research}

The samples for this study consisted of family caregivers who were already in contact with a resource about dementia or part of a network for family caregivers who apparently had an interest in learning more about caring for someone with dementia. Both the Alzheimer's' Association and the researcher who maintained the permission has been granted for this version to appear in e-Publications@Marquette. SAGE Publications does not grant permission for this article to be further copied/distributed or hosted elsewhere without the express permission from SAGE Publications. 
Caregiver Registry provided educational programs for family caregivers related to dementia. Further research is needed to identify what family caregivers of older adults who are not cognitively impaired know about delirium, particularly family caregivers who are not associated with or in contact with organizations that provide targeted education on dementia. Although there are multiple causes of delirium, older adults who are hospitalized, those above 70 years of age, and those with a history of diabetes mellitus, stroke, or depression, are at risk of developing delirium regardless of whether they have dementia (Koster, Hensens, Schuurmans, \& van der Palen, 2011; Rudolph et al., 2009; Van Rompaey et al., 2009). Researchers and program planners might want to target family caregivers for older adults with risk factors for delirium for education programs. In addition, further research is needed on delirium prevention and interventions across the continuum of care. Much of the research on delirium has been conducted in acute care hospitals with limited attention to home care. Family caregivers might play key roles in partnering with health care providers in early recognition of symptoms across the continuum of care. However, research is also needed on health care providers' response to observations from family caregivers given Fick and Foreman's (2000) findings that health care providers ignored family caregivers' observations about behavior changes in their older adult family member.

There is also a need for research with family caregivers who are more diverse than our samples and those who are non-English speaking. The growing Hispanic population, the significant numbers of immigrants with limited English skills, and family caregivers who have health care views that vary from the allopathic paradigm require research that considers variations in health literacy levels and cultural influences.

Given that the findings of this study suggest that family caregivers need information about delirium and are receptive to receipt of information, it is important to conduct research on the outcomes of these educational interventions. Identifying whether education on delirium improves recognition of symptoms, results in appropriate action, and ultimately leads to improved functional outcomes for older adults is critical. These educational interventions might target family caregivers of older adults who are hospitalized,

Journal of Applied Gerontology, Vol 35, No. 7 (July 2014): pg. 744-758. DOI. This article is @ SAGE Publications and permission has been granted for this version to appear in e-Publications@Marquette. SAGE Publications does not grant permission for this article to be further copied/distributed or hosted elsewhere without the express permission from SAGE Publications. 
NOT THE PUBLISHED VERSION; this is the author's final, peer-reviewed manuscript. The published version may be accessed by following the link in the citation at the bottom of the page.

those in nursing homes, or those residing in the community who are at risk of delirium.

Declaration of Conflicting Interests The authors declared no potential conflicts of interest with respect to the research, authorship, and/or publication of this article.

Funding The authors received financial support from the Marquette University College of Nursing Frenn Award for the the mailed survey, and no financial for the Internet survey, or for authorship, and/or publication of this article.

\section{References}

Alzheimer's Association. (2010). Alzheimer's disease facts and figures. Chicago, IL: Author.

Bellelli G., Frisoni G. B., Turco R., Lucchi E., Magnifico F., Trabucchi M., Ferrucci L. (2007). Delirium superimposed on dementia predicts 12month survival in elderly patients discharged from a post-acute rehabilitation facility. Journals of Gerontology, Series A: Biological Sciences and Medical Sciences, 62, 1306-1309.

Bond S. (2009). Delirium at home: Strategies for home health clinicians. Home Healthcare Nurse, 27, 24-34.

Boustani M., Baker M. S., Campbell N., Munger S., Hui S. L., Castelluccio P., Callahan C. (2010). Impact and recognition of cognitive impairment among hospitalized elders. Journal of Hospital Medicine, 5, 69-75.

Bruera E., Bush S., Willey J., Paraskevopoulos T., Zhijun L., Palmer J., Elsayem A. (2009). Impact of delirium and recall on the level of distress in patients with advanced cancer and their family caregivers. Cancer, 115, 2004-2011.

Bull M. J. (2011). Delirium in older adults attending adult day care. International Journal of Older People Nursing, 6, 85-92.

Bunz U. (2009). A generational comparison of gender, computer anxiety, and computer-email web fluency. Studies in Media \& Information Literacy Education, 9, 54-69.

Buss M., Vanderwerker L. C., Inouye S. K., Zhang B., Block S. D., Prigerson H. G. (2007). Associations between caregiver perceived delirium and generalized anxiety. Journal of Palliative Care Medicine, 10, 10831091.

Journal of Applied Gerontology, Vol 35, No. 7 (July 2014): pg. 744-758. DOI. This article is @ SAGE Publications and permission has been granted for this version to appear in e-Publications@Marquette. SAGE Publications does not grant permission for this article to be further copied/distributed or hosted elsewhere without the express permission from SAGE Publications. 
Chiu T. M., Eysenbach G. (2010). Stages of use: Consideration, initiation, utilization, and outcomes of an internet-mediated intervention. Medical Informatics \& Decision Making, 10, Article 73.

Dasgupta M., Hillier L. (2010). Factors associated with prolonged delirium: A systematic review. International Psychogeriatrics, 22, 373-394.

Edelman L. S., Rumei Y., Maughan G., Olson L. M. (2013). Survey methods and response rates among rural community dwelling older adults. Nursing Research, 62, 286-291.

Fick D. M., Agostini J., Inouye S. K. (2002). Delirium superimposed on dementia: A systematic review. Journal of the American Geriatrics Society, 50, 1723-1732.

Fick D. M., Foreman M. (2000). Consequences of not recognizing delirium superimposed on dementia in hospitalized elderly individuals. Journal of Gerontological Nursing, 26, 30-40.

Fong T. G., Jones R. N., Shi P., Marcantonio E. R., Yap L., Rudolph J. L., Inouye S. K. (2009). Delirium accelerates cognitive decline in Alzheimer disease. Neurology, 72, 1570-1575.

González M., Martínez G., Calderón J., Villarroel L., Yuri F., Rojas C., Carrasco M. (2009). Impact of delirium on short-term mortality in elderly inpatients. Psychosomatics, 50, 234-238.

Greer N., Rossom R., Anderson P., MacDonald R., Tacklind J., Rutks I., Wilt T. (2011). Delirium: Screening, prevention and diagnosis $-A$ systematic review of evidence. Washington, DC: Department of Veterans Affairs.

Hayden L. J., Glynn S. M., Hahn T. J., Randall F., Randolph E. (2012). The use of Internet technology for psychoeducation and support with dementia caregivers. Psychological Services, 9, 215-218.

Kiely D. K., Marcantonio E. R., Inouye S. K., Shaffer M., Bergmann M., Yang F. M., . . .Jones R. N. (2009). Persistent delirium predicts greater mortality. Journal of the American Geriatrics Society, 57, 55-61.

Koster S., Hensens A., Schuurmans M. J., van der Palen J. (2011). Risk factors of delirium after cardiac surgery: A systematic review. European Journal of Cardiovascular Nursing, 10, 197-204.

Leslie D. L., Inouye S. K. (2011). The importance of delirium: Economic and societal costs. Journal of the American Geriatrics Society, 59(Suppl. 2), S241-S243

Leslie D. L., Marcantonio E. R., Zhang Y., Leo-Summers L., Inouye S. (2008). One year health care costs associated with delirium in the elderly population. Archives of Internal Medicine, 168, 27-32. 
Lewis M. L., Hobday J. V., Hepburn K. W. (2010). Internet-based program for dementia caregivers. American Journal of Alzheimer's Disease \& Other Dementias, 25, 674-679.

Martinez F. T., Tobar C., Beddings C., Vallejo G., Fuentes P. (2012). Preventing delirium in an acute hospital using a non-pharmacological intervention. Age and Ageing, 41, 629-634.

Meagher D., Leonard J., Donnelly S., Conroy M., Adamis D., Trzepacz P. (2011). A longitudinal study of motor subtypes of delirium:

Relationship with phenomenology, etiology, medication exposure and prognosis. Journal of Psychosomatic Research, 71, 395-403.

Meier D. E. (2012). Pain as a cause of agitated delirium. Archives of Internal Medicine, 172(15), 1130.

Mittal V., Muralee S., Williamson D., McEnerney N., Thomas J., Cash M., Tampi R. R. (2011). Delirium in the elderly: A comprehensive review. American Journal of Alzheimer's Disease \& Other Dementias, 26, 97109

National Alliance for Caregiving and American Association of Retired Persons. (2009). Caregiving in the U.S. Retrieved from http://www.caregiving.ord/pdf/research/CaregivingintheUS2009fullrep ort.pdf

Naylor M. D., Hirschman K. B., Bowles K., Bixby M., Konick-McMahan J., Stephens C. (2007). Care coordination for cognitively impaired older adults and their caregivers. Home Health Services Quarterly, 26(4), 57-78.

Polit D., Beck C. (2012). Nursing research. Philadelphia, PA: Lippincott Williams \& Wilkins.

Quinlan N., Rudolph J. L. (2011). Postoperative delirium and functional decline after noncardiac surgery. Journal of the American Geriatrics Society, 59, S301-S304.

Quinn K. (2010). Methodological considerations in surveys of older adults: Technology matters. International Journal of Emerging Technologies and Society, 8, 114-133.

Rahkonen T., Mäkelä H., Paanila S., Halonen P., Sivenius J., Sulkava R. (2000). Delirium in elderly people without severe predisposing disorders: Etiology and 1-year prognosis after discharge. International Psychogeriatrics, 12, 473-481.

Rudolph J. L., Jones R. N., Levkoff S. E., Rockett C., Inouye S. K., Sellke F. W., Marcantonio E. R. (2009). Derivation and validation of a preoperative prediction rule for delirium after cardiac surgery. Circulation, 119, 229-236.

Journal of Applied Gerontology, Vol 35, No. 7 (July 2014): pg. 744-758. DOI. This article is @ SAGE Publications and permission has been granted for this version to appear in e-Publications@Marquette. SAGE Publications does not grant permission for this article to be further copied/distributed or hosted elsewhere without the express permission from SAGE Publications. 
NOT THE PUBLISHED VERSION; this is the author's final, peer-reviewed manuscript. The published version may be accessed by following the link in the citation at the bottom of the page.

Rudolph J. L., Zanin N. M., Jones R. N., Marcantonio E. R., Fong T. G., Yang F. M., Inouye S. K. (2010). Hospitalization in community dwelling persons with Alzheimer's disease. Journal of the American Geriatrics Society, 58, 1542-1548.

Sykes L. L., Walker R. L., Ngwakongnwi E., Quan H. (2010). A systematic literature review on response rates across racial and ethnic populations. Canadian Journal of Public Health, 101, 213-219.

Sykes P. K. (2012). Prevention and management of postoperative delirium among older patients on an orthopedic surgical unit: A best practice implementation project. Journal of Nursing Care Quality, 27, 146-153.

Teel C., Meek P., McNamara A. M., Watson L. (1997). Perspectives in unifying symptom interpretation. Image: Journal of Nursing Scholarship, 29, 175-181.

Van Rompaey B., Elseveiers M., Schuurmans M. J., Shortridge-Baggett L. M., Truijen S., Bossaert L. (2009). Risk factors for delirium in intensive care patients: A prospective cohort study. Critical Care, 13(3), Article R77.

Wang J., Mentes J. (2009). Factors determining nurses' clinical judgments about elderly patients with acute confusion. Issues in Mental Health Nursing, 30, 399-405.

Witlox J., Eurelings L. S., de Jonghe J. F., Kalisvaart K., Eikelenboom P., van Gool W. A. (2010). Delirium in elderly patients and the risk of postdischarge mortality, institutionalization, and dementia. Journal of the American Medical Association, 304, 443-451.

Journal of Applied Gerontology, Vol 35, No. 7 (July 2014): pg. 744-758. DOI. This article is @ SAGE Publications and permission has been granted for this version to appear in e-Publications@Marquette. SAGE Publications does not grant permission for this article to be further copied/distributed or hosted elsewhere without the express permission from SAGE Publications. 